\title{
Research Progress on Morphological Changes and Surgery-Related Parameters of Corneal Cap in Small-Incision Lenticule Extraction
}

\author{
Chen Liang Yan Zhang Yuxi He Shurong Wang \\ Corneal Refraction Department, The Second Hospital of Jilin University, Changchun, China
}

\section{Keywords}

Small-incision lenticule extraction · Corneal cap .

Re-treatment $\cdot$ Surgical parameters $\cdot$ Complication

\begin{abstract}
Small-incision lenticule extraction (SMILE) is an "all-in-one" surgical method for refractive correction. An advantage of the SMILE over traditional surgery is that it depends on the corneal cap's design. This review discusses the morphological evaluation of the corneal cap, selection of the corneal cap with different thicknesses and diameters, influence of the corneal cap design on re-treatment, and management of corneal cap-related complications. The following points should be recognized to define the correct morphology and design of the operation-related parameters of the corneal cap during SMILE: (1) the thickness and diameter of the corneal cap are predictable and influence postoperative visual quality, (2) the change in the anterior surface curvature of the corneal cap should be considered in the design of the nomogram value, (3) for patients with moderate myopic correction, early visual quality is better with a $6.9-\mathrm{mm}$ than with a 7.5-mm-diameter corneal cap, (4) there is no significant difference in visual quality or biomechanics among corneal caps with different thicknesses, (5) the primary corneal cap thickness plays an important role in the SMILE re-treatment, (6) a 7.78-mm diameter corneal cap has a greater risk of suction loss than a 7.60-mm diameter corneal cap, (7) if suction
\end{abstract}

karger@karger.com www.karger.com/ore

Karger"
(C) 2021 The Author(s)

Published by S. Karger AG, Basel

This is an Open Access article licensed under the Creative Common Attribution-NonCommercial-4.0 International License (CC BY-NC) (http://www.karger.com/Services/OpenAccessLicense), applicable to the online version of the article only. Usage and distribution for commercial purposes requires written permission. loss occurs when lenticular scanning exceeds $10 \%$, then SMILE can be continued by changing the corneal cap thickness, (8) preventive collagen cross-linking with SMILE caps are $90-120 \mu \mathrm{m}$ thick and 7-7.8 $\mathrm{mm}$ in diameter, and (9) properly treating SMILE-related complications ensures better postoperative results. The data presented herein shall deepen the understanding of the importance of the corneal cap during SMILE and provide diversified analysis for personalized operational design of corneal cap parameters.

(c) 2021 The Author(s)

Published by S. Karger AG, Basel

\section{Introduction}

Small-incision lenticule extraction (SMILE) is an "allin-one" corneal refractive surgery that was first introduced in 2011. This procedure corrects myopia or myopic astigmatism and has been widely accepted by doctors and patients, owing to its excellent safety, effectiveness, stability, and predictability [1]. The procedure involves scanning the corneal stroma at different depths using a femtosecond laser, cutting the lenticule and creating a corneal cap and extracting the lenticule through a $2.0-4.0-\mathrm{mm}$ incision on the side of the corneal cap. Compared with the traditional "flap" operation, SMILE reduces wound-

Chen Liang and Yan Zhang share the first authorship.
Correspondence to:

Shurong Wang, srwang@jlu.edu.cn 


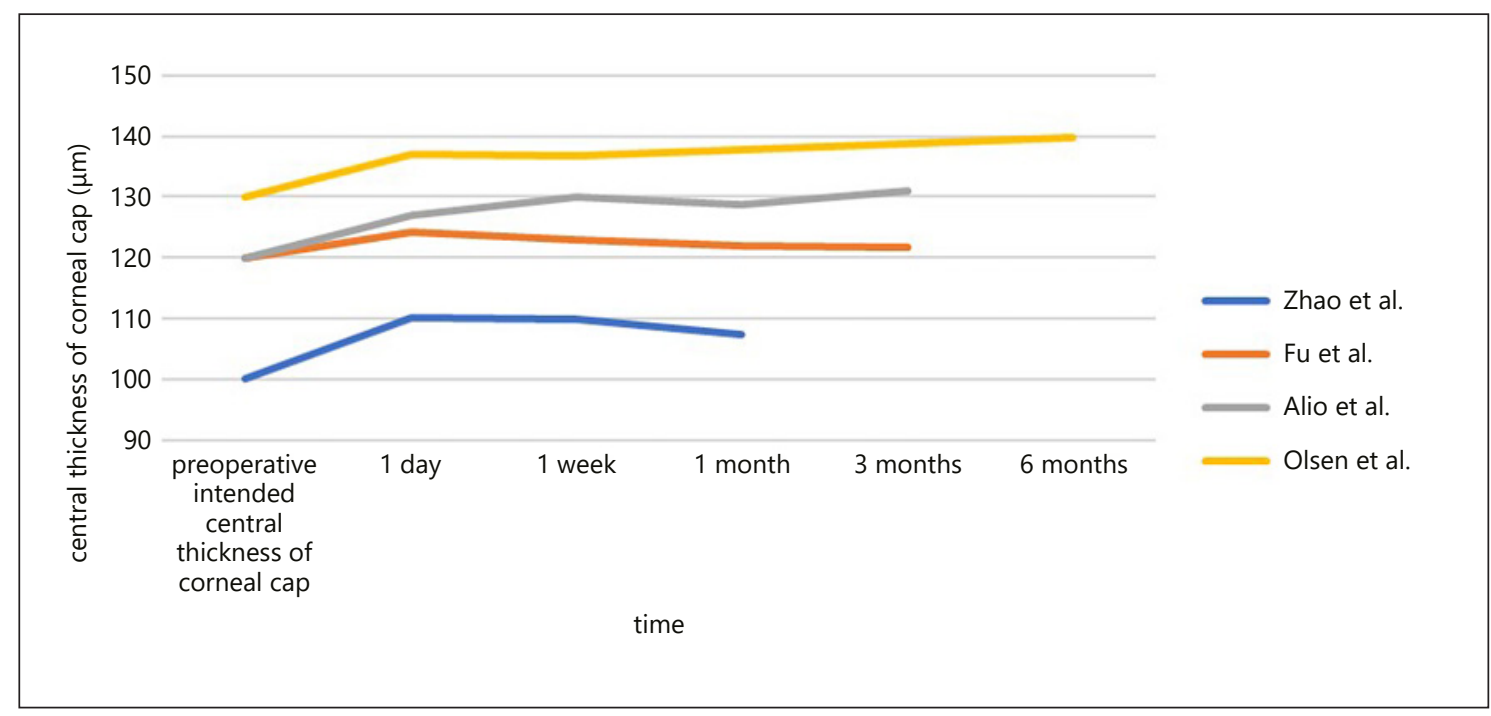

Fig. 1. Changes in the central thickness of different corneal caps over time. Several studies have shown that the postoperative central corneal cap thickness is significantly greater than that expected and stabilizes over time.

healing responses, owing to the small incision design [2]. The biomechanical strength of the cornea after SMILE is reportedly greater than that observed, following photorefractive keratectomy and laser-assisted in situ keratomileusis (LASIK) [3, 4]. Furthermore, SMILE causes less damage to the corneal nerve fibers, and the risk of dry eyes following surgery is significantly lower with SMILE than with femtosecond lenticule extraction (LE) [5].

One of the advantages of SMILE is the creation of the corneal cap. Unlike the lenticule, the corneal cap does not function in vision correction. However, the cap is important to ensure surgical success and reduce postoperative complications. The surgical design around the cap thickness is an important problem faced by surgeons. Different thicknesses of the corneal cap may affect the postoperative visual quality and corneal biomechanics of patients and may affect whether the remaining stromal thickness is within the safe range of surgery. In addition, if refractive regression occurs after surgery, the corneal cap thickness could play a role in the re-treatment. Finally, especially for less-experienced surgeons, the management of corneal cap-related complications should be considered.

\section{Morphological Changes in the Corneal Cap}

One of the characteristics of SMILE is that it is a flapless procedure, and designing a regular corneal cap is one of the key steps to ensure the accurate creation of a lenticule. Therefore, a deep understanding of the morpho- logical changes in corneal caps is necessary. At present, most studies have focused on changes in the corneal cap thickness and diameter. It is believed that with the continuous improvement of technology, the study of the corneal cap area or volume will receive more attention.

\section{Predictability of the Corneal Cap Thickness}

It is reported that although the corneal cap becomes thicker than the preoperative intended value, the predictability of the cap thickness remains good and is consistent with the low error rate of femtosecond laser ablation [6]. The predictability of the corneal cap thickness is evaluated by the difference between the preoperative and postoperative thickness of the corneal cap.

Several studies have shown that the postoperative central corneal cap thickness is significantly greater than expected (shown in Fig. 1) and stabilizes over time [6-9]. These results are consistent with the accuracy range of -11 to $+14 \mu \mathrm{m}$ for the cap thickness as described by Reinstein et al. [10]. Conversely, the flap thickness of LASIK tends to become thinner from the first day to the first week following operation and then gradually increases 1 month following the operation [11].

Olsen et al. [9] conducted a 6-month follow-up study of SMILE by using a cap thickness of $130 \mu \mathrm{m}$, designed before the operation. The authors found that the thicknesses of the central corneal cap (average corneal cap thickness, 0.5 and $1.0 \mathrm{~mm}$ from the apex) and peripheral central corneal cap (average corneal cap thickness, 1.5, 2.0 , and $2.5 \mathrm{~mm}$ from the apex) were greater than those 
before surgery. They also reported that the corneal cap thickness in patients with low myopia was less than that in patients with moderate and high myopia at 1 and 6 months following surgery. The change in the corneal cap thickness may be related to stromal edema, epithelial remodeling, and wound-healing responses [12].

\section{Uniformity of the Corneal Cap}

Maintaining good uniformity of the corneal cap may contribute to the safety of surgery by preserving the remaining stromal bed thickness and reducing the occurrence of spherical aberration of the cornea. The uniformity of the corneal cap is characterized by the fact that its thickness gradually increases from the center to the periphery [7].

The reasons for this shape may be related to the following factors: (1) differences in the femtosecond-laser scanning sequence on the front and rear surfaces of the lenticule, which may lead to a delay effect [13] of peripheral fibers and cavitation overworked of fibers and (2) damages in the central cornea caused by the laser despite that the corneal matrix in the periphery may retain strong tensile strength.

\section{Regularity of the Corneal Cap}

In SMILE, the regularity of the corneal cap indirectly reflects the morphological changes in the lenticule, such as the emergence of a tissue bridge [14]. The symmetrical distribution of the corneal thickness at the same distance from the corneal apex is described as the regularity of the corneal cap [7].

Similar regularity is related to the visual quality in LASIK surgery [15]. In addition, Fu et al. [7] found that differences in the thickness (the thickest point minus the thinnest point) were related to the objective scattering index. Compared with the preset corneal cap diameter of $7.5 \mathrm{~mm}$ before surgery, the mean horizontal and vertical radial cap diameters were $7.61 \pm 0.07 \mathrm{~mm}$ and $7.57 \pm 0.06$ $\mathrm{mm}$, respectively, 1 month following the operation, which showed good repeatability. On the contrary, Holzer et al. [16] demonstrated that the flap diameter for an intended size between 8.0 and $9.5 \mathrm{~mm}$ was within a range of \pm 0.4 $\mathrm{mm}$, while the median at the maximum was $0.3 \mathrm{~mm}$ off. Binder et al. [17] also reported a similar situation, stating that the maximum diameter of the flap measured after the operation was $0.6 \mathrm{~mm}$, when compared with the expected diameter.

\section{Anterior Surface Curvature of the Corneal Cap}

The features of the large central curvature and small periphery of the corneal cap after SMILE are consistent with the shape of maintaining corneal asphericity [18]. Moreover, the decrease in curvature remains stable long after the operation.

Qin et al. [19] studied the curvature stability of the corneal cap in the early stage after SMILE-corrected high myopia and found that a curvature of $4 \mathrm{~mm}$ in the central area of the corneal cap decreases significantly after the operation, whereas there is no difference between 1 day and 6 months after the operation. Xia et al. [20] observed long-term changes in the curvature of the central $4-\mathrm{mm}$ zone of the corneal cap after the correction of high myopia. The study showed that the curvature value of this area decreases significantly 5 years after the operation but increases slightly and remains stable 5-7 years after the operation compared with the value in the previous followup. Yang et al. [21] measured a curvature change of $3 \mathrm{~mm}$ in the center of the cap after SMILE-corrected high myopia and observed that the curvature decreases by $-0.43 \pm$ $0.54 \mathrm{D}$ from 1 to 5 months after the operation, which is related to the slight refractive regression of $-0.24 \mathrm{D}$ and an increase of $0.20 \mu \mathrm{m}$ in spherical aberration after the operation.

An in vitro study [22] showed that for a myopic correction of $-8 \mathrm{D}$, the curvature of the anterior surface of the corneal cap in the $110-\mu \mathrm{m}$ cap thickness group is lesser than that in the 160- $\mu \mathrm{m}$ thickness group. Wu et al. [23] also found small changes in the curvature of the $4-\mathrm{mm}$ area in the anterior surface of the corneal cap after the operation in the $140-\mu \mathrm{m}$ group compared with that in the $110-\mu \mathrm{m}$ group.

The arrangement of collagen fibers is responsible for stability of the curvature of the anterior surface of the corneal cap [24]. The curvature of the thinner cap varies greatly because the lenticule includes more anterior stroma. Therefore, it is necessary that eyes with thicker corneal caps compensate for possible under-correction caused by less flat surfaces, by increasing the nomogram value.

\section{Parameters Related to the Surgical Design of the Corneal Cap}

Selection of the Thickness and Diameter of the Corneal Cap

Since morphological changes in the corneal cap are relatively stable, it is important to design the corneal cap before the operation. The thickness of the corneal cap can be designed to be $100-160 \mu \mathrm{m}[1,25]$. The range of the corneal cap diameter recommended by the equipment manu-
Liang/Zhang/He/Wang 
facturer is $5.00-8.00 \mathrm{~mm}$. In 2018, Chinese experts recommended that the thickness of the corneal cap should be 110-120 $\mu \mathrm{m}$. Clinicians choose different cap thicknesses based on the central corneal thickness and correction of diopter (D) that would be attempted. There are 2 main postoperative outcomes: corneal biomechanics and visual quality. An improper thickness selection may damage the tensile strength of the cornea, thus increasing the difficulty of lenticule removal and risk of iatrogenic ectasia [26]. Furthermore, different cap thicknesses may affect the asphericity of the cornea, which is closely associated with changes in wavefront aberration and effective optical zone [27].

\section{Influence of the Corneal Cap Thickness on Corneal}

Biomechanics

The anterior one-thirds of the corneal stroma has stronger biomechanics than the posterior two-thirds [28]. As the depth increases, the collagen lamellae in the anterior corneal stroma are arranged in parallel, and the distance between them is gradually increased [29], which makes the extraction of the lenticule easier [30,31]. However, most studies have not found significant differences in corneal biomechanics among corneal caps with different thicknesses [30, 32].

Liu et al. [33] compared the biomechanics between corneal caps that were $110 \mu \mathrm{m}$ or $150 \mu \mathrm{m}$ thick. The authors found that there were no differences in the first and second applanation time, peak distance, or deformation amplitude between the 2 groups at 3 months following surgery. However, they did observe that the corrected intraocular pressure changed less in eyes with a $150-\mu \mathrm{m}$ thick cap. To compare the biomechanical strength of corneal caps of 110 and $160 \mu \mathrm{m}$ in thickness, Damgaard et al. [22] performed SMILE surgery on donor corneas with the epithelium removed. As the pressure in the chamber increased, the change in the curvature of the front surface of the $110-\mu \mathrm{m}$ cap was greater than that of the $160-\mu \mathrm{m}$ cap for -8 D SMILE. In addition, in a contralateral eye study, a $100-\mu \mathrm{m}$ thick cap showed less corneal hysteresis and corneal resistance factor than a 160$\mu \mathrm{m}$ thick cap [34]. However, whether these 2 parameters represent the overall characteristics of the biomechanics should be viewed with caution [35].

The elevation of the posterior surface of the cornea is an early sign of corneal ectasia [36]. Animal and clinical studies have shown that the posterior corneal elevation does not move forward following SMILE surgery with different cap thicknesses but tends to move backward [30, 32]. However, when the residual bed thickness is $<250$ $\mu \mathrm{m}$, the posterior corneal elevation of a $150-\mu \mathrm{m}$ thick cap is steeper than that of a $110-\mu \mathrm{m}$ thick cap [22].

Morphology and Surgical Parameters of

Corneal Cap in SMILE
Influence of the Corneal Cap Thickness on Visual Quality

Previous studies have reported that in the stable postoperative period (3 months), there is no difference in the postoperative visual quality as measured by the spherical equivalent, visual acuity, and high-order aberrations [24, $30,31,33,34]$. These results reflect the safety and effectiveness of SMILE [25, 31].

Liu et al. [33] compared corneal cap thicknesses of 110 $\mu \mathrm{m}$ and $150 \mu \mathrm{m}$ and found that the uncorrected visual acuity, objective visual quality parameters (Strehl ratio, objective scattering index, and modulation transfer function), and contrast sensitivity at the medium spatial frequency were greater in eyes with a cap thickness of 110 $\mu \mathrm{m}$ in the early postoperative stage ( 1 day) than in those with a cap thickness of $150 \mu \mathrm{m}$. However, the incidence of an opaque bubble layer (OBL) in 110- $\mu$ m corneal caps was also higher. Wu et al. [37] quantitatively analyzed the area and density of the OBL in $110-\mu \mathrm{m}$ and $140-\mu \mathrm{m}$ caps following SMILE and concluded that the thinner the cap, the greater the probability of the OBL and that the presence of a moderate or severe OBL may affect vision.

Research by Damgaard et al. [22] on donor corneas revealed the same trend in both $-4 \mathrm{D}$ and $-8 \mathrm{D}$ correction surgery. The anterior and posterior surfaces of the cornea were steeper following the $160-\mu \mathrm{m}$ cap operation, and the difference was more obvious in the $-8 \mathrm{D}$ correction. These results may suggest that for patients with high myopia, there is a risk of under-correction when choosing a thicker corneal cap.

Liu et al. [31] examined the smoothness of the lenticule surface by scanning electron microscopy and found that the front surface of the lenticule produced by a cap depth of $120 \mu \mathrm{m}$ was rougher than that produced by a $140-\mu \mathrm{m}$ cap. This result was contrary to that reported by Weng et al. [25], who concluded that the lenticules produced by $120-\mu \mathrm{m}$ and $130-\mu \mathrm{m}$ caps were smoother than that produced by $140-\mu \mathrm{m}$ and $150-\mu \mathrm{m}$ caps following qualitative and quantitative analysis of the tissue bridge on the lenticule surface. Since lenticule smoothness is associated with postoperative visual quality, further investigations on this topic are warranted.

Dry eye is an inevitable problem following corneal refractive surgery and affects patient's subjective visual experience. Yang et al. [38] evaluated corneal nerve destruction following SMILE in patients who had corneal cap thicknesses of $100 \mu \mathrm{m}$ and $120 \mu \mathrm{m}$. There were no differences in the density and number of nerve fibers under the basement membrane between these groups at 1 week following surgery.

Ophthalmic Res 2022;65:4-13

DOI: $10.1159 / 000520241$ 
Table 1. Comparisons of SMILE enhancement surgeries

\begin{tabular}{|c|c|c|c|c|c|c|}
\hline $\begin{array}{l}\text { Surgical } \\
\text { methods }\end{array}$ & $\begin{array}{l}\text { Primary } \\
\text { corneal cap } \\
\text { thickness, } \mu \mathrm{m}\end{array}$ & $\begin{array}{l}\text { Safety and } \\
\text { efficacy }\end{array}$ & $\begin{array}{l}\text { Flap or } \\
\text { flapless }\end{array}$ & $\begin{array}{l}\text { Enhance } \\
\text { hyperopia } \\
\text { or myopia }\end{array}$ & Advantage & Disadvantage \\
\hline $\begin{array}{l}\text { Excimer laser } \\
\text { ablation }\end{array}$ & Any & Good & Flapless & Both & $\begin{array}{l}\text { The simplest surgical method } \\
\text { Little biomechanical change }\end{array}$ & $\begin{array}{l}\text { Slow healing reaction } \\
\text { The risk of haze } \\
\text { The use of mitomycin C }\end{array}$ \\
\hline Thin-flap LASIK & $\geq 120$ & Good & Flap & Both & Little biomechanical change & $\begin{array}{l}\text { Must consider a safe distance between the } \\
\text { corneal epithelium and the initial operation } \\
\text { interface } \\
\text { The risk of flap-related complications }\end{array}$ \\
\hline CIRCLE & $\leq 120$ & Good & Flap & Both & $\begin{array}{l}\text { VisuMax owns the program, } \\
\text { convenient } \\
\text { Rapid recovery }\end{array}$ & Increased changes in biomechanics \\
\hline ReSMILE* & $\geq 140$ & Good & Flapless & Myopia & $\begin{array}{l}\text { The most rapid healing } \\
\text { Little biomechanical change }\end{array}$ & Difficult surgical method \\
\hline Sub-cap LE** & $\leq 130$ & - & Flapless & Myopia & - & - \\
\hline
\end{tabular}

LASIK, laser-assisted in situ keratomileusis; SMILE, small-incision lenticule extraction; Sub-cap LE, sub-cap lenticule extraction; reSMILE, secondary smallincision lenticule extraction. * The secondary LE plane is in front of the primary plane. ${ }^{*}$ A case report: the safety, efficacy, advantages, and disadvantages of this method need further study.

Influence of the Corneal Cap Diameter on Visual

Quality

Since SMILE does not have an iris-tracking device to the center, postoperative eccentricity would induce highorder aberrations. Moreover, the diameter of the corneal cap is related to intraoperative centration.

In a study by Torun Acar et al. [39], the diameter of the optical zone designed before the operation was $6.5 \mathrm{~mm}$, and subsequently, the visual quality of the corneal caps with diameters of $6.9 \mathrm{~mm}$ and $7.5 \mathrm{~mm}$ was compared. The authors found that uncorrected distance visual acuity of $6.9 \mathrm{~mm}$ was greater in the early postoperative period. Furthermore, fewer instances of total high-order aberrations, horizontal and vertical coma, and spherical aberrations were noted at 6 months following surgery in patients with cap diameters of $6.9 \mathrm{~mm}$.

\section{Influence of the Corneal Cap Design on Re-Treatment Options}

Although SMILE surgery has been favored by many doctors and patients, the re-treatment rate is still low (2.3-4.4\%) [40-42]. According to a study by Liu et al. [42] on enhanced surgery following SMILE, the average spherical equivalent of 524 eyes that underwent enhancement was $-0.50 \pm 0.86 \mathrm{D}$, which was a low myopic correction. The methods for enhancement surgery can be summarized as follows: excimer laser ablation [40], thin-flap LASIK [41], CIRCLE [43], and secondary SMILE.

\section{Excimer Laser Ablation}

Excimer laser ablation is the simplest enhancement surgery because it can be performed without considering the thickness of the initial cap [44]. However, patients need to accept certain disadvantages resulting from excimer laser ablation (such as slow recovery).

\section{Thin-Flap LASIK}

For thin-flap LASIK, a thin flap on the patient's initial corneal cap is made, and subsequently, conventional LASIK is performed. Reinstein et al. [45] suggested that the prerequisite for successful secondary LASIK with a thin flap is the presence of at least $40 \mu \mathrm{m}$ of space between the maximum epithelial thickness and the minimum cap thickness. Considering some postoperative reactions, such as epithelial thickening following the first SMILE operation [46], the initial cap thickness is designed to be $\geq 120 \mu \mathrm{m}$ [47].

\section{CIRCLE}

CIRCLE is achieved by changing the initial corneal cap into a corneal flap with femtosecond laser and then performing femtosecond-laser-assisted LASIK. When the initial cap thickness is $<120 \mu \mathrm{m}$ [48], the VisuMax CIRCLE program (Carl Zeiss Meditec AG, Jena, Germany) $[43,45]$ can be considered. However, if the CIRCLE program is performed in a thick cap, such as caps of 150-160 $\mu \mathrm{m}$ thickness, it will inevitably cause damage to the corneal biomechanics [49]. 
Secondary SMILE

SMILE is still selected for enhancement, which could be performed by 2 methods: (1) secondary LE, where the plane is in front of the primary plane [48] and (2) sub-cap LE, where the plane is behind the primary plane [50]. When the initial corneal cap thickness is $\geq 140 \mu \mathrm{m}$ and the secondary correction $\mathrm{D}$ is $\geq-1.00 \mathrm{D}$, the secondary SMILE procedure could be performed to maintain the flapless characteristic and minimize the wound-healing response [48]. If the initial cap thickness is $110-130 \mu \mathrm{m}$, the depth limit makes it impossible to extract the lenticule in front of the original interface. In this case, the initial operation interface can be used as the front surface of the new lenticule. This method is known as sub-cap LE [50]. However, considering the safety range of the remaining stromal-bed thickness, Riau et al. [48] recommended that the primary cap thickness should be designed to be $\leq 130$ $\mu \mathrm{m}$. The selection of the cap thickness corresponding to each method and other factors to be considered are presented in Table 1.

\section{Application of the Corneal Cap Thickness and}

Diameter in Collagen Cross-Linking with SMILE

Compared with "flap" surgery, SMILE has greatly improved the biomechanics due to its unique cap design to protect the anterior stroma. However, corneal ectasia is still reported after SMILE surgery [51-53]. Corneal collagen cross-linking (CXL) can prevent or delay the progression of corneal ectasia by improving the biomechanics of the corneal stroma $[54,55]$. Collagen cross-linking with SMILE (SMILE Xtra) is undoubtedly a choice to prevent postoperative corneal ectasia in young patients, with a high refractive power and thin cornea, as determined by preoperative screening. At present, the parameters of caps with different thicknesses or diameters are not unified. Irradiation energy and the selected cap diameter and thickness affect the extent of cross-linking.

$\mathrm{Ng}$ et al. [56] studied the early clinical effect of SMILE Xtra on myopia. They used a corneal cap thickness of $110-120 \mu \mathrm{m}$ and a cap diameter of 7.0-7.5 mm. After 6 months, SMILE Xtra had good predictability. In addition, 1 year after SMILE Xtra, CXL under a cap with a thickness of $120 \mu \mathrm{m}$ and a diameter of $7.6 \mathrm{~mm}$ also achieved good safety, effectiveness, predictability, and stability [57].

Ganesh et al. [58] performed myopia correction by SMILE Xtra under a cap thickness of $100 \mu \mathrm{m}$ and cap diameter of 7-7.5 mm. All 40 eyes studied maintained stable visual quality and corneal morphology at 1 year after the operation. Konstantopoulos et al. [59] compared the corneal stability with SMILE Xtra and CXL with LASIK. They cross-linked SMILE under a cap with a depth of 120 $\mu \mathrm{m}$ and a diameter of $7.5 \mathrm{~mm}$ and found no difference in the changes in the posterior corneal elevation and corneal thickness between SMILE Xtra and CXL with LASIK after the operation. Osman et al. [60] performed SMILE Xtra on patients with corneas thinner than $520 \mu \mathrm{m}$. The thickness of the corneal cap was $90 \mu \mathrm{m}$, and the diameter was $7.5 \mathrm{~mm}$. One year after the operation, $94 \%$ of the eyes obtained an uncorrected distance visual acuity of 20/30 or above, and the biomechanics was significantly higher than that with traditional SMILE. Zhou et al. [61] observed corneal morphological changes after SMILE Xtra by optical coherence tomography and in vivo confocal microscopy. In their study, the ultraviolet radiation of riboflavin was carried out under a cap with a thickness of $110-120 \mu \mathrm{m}$ and a diameter of 7-7.8 mm. Six months after the surgery, the researchers observed hyper-reflectivity in the corneal tissue with a cap thickness of $60 \mu \mathrm{m}$ to a stromal bed of $388 \mu \mathrm{m}$, an indirect sign of corneal cross-linking, illustrating the extent of corneal crosslinking.

Because the anterior stroma with high collagen-fiber density is the main site of cross-linking, a thicker cap is expected to reduce the concentration gradient of riboflavin permeation to the cap and stromal bed [62-64]. The selection of different cap diameters is also related to the volume of the stromal pocket.

\section{Management of Corneal Cap-Related Complications}

SMILE has helped achieve encouraging results in correcting myopia and myopic astigmatism. However, it is undeniable that the long learning curve of surgery could lead to certain complications. Corneal cap-related complications include suction loss, cap perforation, cap lenticular adhesion, and cap striae. Therefore, it is necessary to consolidate the doctors' understanding and management of corneal cap-related complications.

\section{Suction Loss}

The morphological characteristics of corneal caps are related to the adsorption stability between the cone and eyes. In addition, corneal caps with different thicknesses also play an important role in the treatment of suction loss.

Suction loss is an intraoperative complication and results in the detachment of the suction cone from the patient's cornea. The development of software combined with experienced operators has reduced the rate of suc- 
tion loss to $0.17-0.93 \%$ [65-70]. Suction loss could result in the decline of postoperative visual quality, and the possibility of this complication should be recognized by the ophthalmologist [71].

In addition to the eye movement, the liquid present at the corneal contact interface may interfere with suction [67]. Osman et al. [67] found that the diameter of the cap, rather than the thickness, was also a potential factor in suction loss, which could be related to poor matching between the cone and the cornea. These data were confirmed by $\mathrm{Ma}$ et al. [72], who found that patients in the control group had a mean cap diameter of $7.60 \mathrm{~mm}$, while the cap diameter in the suction-loss group was $0.18 \mathrm{~mm}$ larger.

The conventional method for managing suction loss is to adopt excimer laser ablation or femtosecond-laser-assisted LASIK when the laser scanning of the lenticule exceeds $10 \%$, while SMILE can be continued after suction loss in other stages [73]. However, Reinstein et al. [74] pointed out that when the thickness of the corneal cap is $\geq 135 \mu \mathrm{m}$, even in the first case, SMILE may be restarted by reducing the thickness of the cap. In addition, Qin et al. [70] adopted an innovative method for increasing the thickness of the corneal cap following suction loss during SMILE, when $>10 \%$ of the back surface of the lenticule had been subjected to scanning, and they achieved good postoperative results. Therefore, changing the corneal cap thickness following suction loss during SMILE surgery could be a plausible alternative for shortening the recovery time or reducing corneal flap complications caused by conventional eye surgeries.

\section{Cap Perforation and Cap Lenticular Adhesion}

Severe cap perforation and cap lenticular adhesion affect the visual outcome. At present, with the emergence of many new technologies, these complications can be well prevented. However, low myopic correction and OBL may increase the difficulty of LE [75]. Therefore, for patients with low myopic correction, the incidence of OBL can be reduced by increasing the thickness of the corneal cap, thus reducing the incidence of cap lenticular adhesion.

Perforation of the corneal cap has been reported during the separation of the front surface of the lenticule [75] and was shown to be related mainly to the clinicians' inexperience. The incidence of cap perforation is $0.25-4.38 \%$ [73]. Ivarsen et al. [71] treated patients with cap perforation by having them wear contact lenses, and only a small scar remained on the corneal surface 3 months following the surgery, which did not affect their vision.
The main reason for cap lenticular adhesion is that OBL interferes with the surgeon's operating visual field and causes disordered anatomy of the lenticule (the normal order is the front surface and the back surface) [76]. At present, various markings have been described to avoid inaccurate positioning of the cutting plane, such as the white ring sign [77], shimmer sign [78], meniscus sign [79], and stop sign [80]. Furthermore, some new technologies have been developed to reduce adhesions, such as Chung's swing technology, which uses a fan shovel to separate the posterior surface of the lenticule [81]; double-crescentic edge separation technology, which uses a Sinskey hook to separate the lenticule [82]; hydroexpression technology, which places an irrigation cannula under the lenticule [83]; and intraoperative optical coherence tomography [84]. These newer technologies are particularly beneficial to less-experienced physicians. For the complete removal of lenticular fragments or residues, which is difficult to separate, a second surgery can also be adopted $[76,85]$.

\section{Cap Striae}

Although cap striae rarely occur, the principles of prevention and treatment are still worthy of attention. A case report described the treatment of patients with moderate and high myopia with cap striae following operation [86]. In the operation of the left eye, owing to the dislocation of the anatomical sequence, the operator performed repeated LE to prevent lenticular adhesion; thus, the tear of the cap incision and cap striae of the cumulative visual axis appeared on the first day following the operation. The patient complained of glare. Doctors flushed the interface with a balanced salt solution, used a scraper to remove the corneal epithelium corresponding to the cap striae, washed the exposed stroma layer with distilled water, stretched the cap striae with a sponge, and finally covered the striae with a bandage contact lens. The cap striae disappeared completely, and the uncorrected distance vision was 20/20 at 9 months after the operation.

Therefore, cap striae caused by excessive operation should be avoided during extraction. Furthermore, it is necessary to flush the surgical interface, which can reduce the risk of epithelial implantation.

\section{Conclusion}

The following points should be considered for the morphological changes and surgery-related parameters of the corneal cap: (1) the corneal cap shows good pre-
Liang/Zhang/He/Wang 
dictability and repeatability both laterally (diameter) and longitudinally (thickness); (2) the anterior surface curvature of the corneal cap is significantly smaller than that before the operation, and this flattening change should be considered in the design of nomogram values, especially when the corneal cap is thick; (3) the corneal cap thickness and morphology influence the postoperative visual quality, and the influence of different cap thicknesses is mainly limited to the first day post-surgery; (4) for patients with moderate myopic correction, the visual quality is greater with a $6.9-\mathrm{mm}$-diameter corneal cap than with a 7.5-mm-diameter cap; (5) there is no significant difference in visual quality and biomechanics between different corneal cap thicknesses during the stable period. These results suggest that for patients with high myopic correction, the thickness of the corneal cap should be reduced to retain a greater depth of the remaining stromal bed. Furthermore, creating a thick cap may cause undercorrection for high myopic patients $(-8 \mathrm{D})$; $(6)$ the thickness of the first corneal cap plays an important role in SMILE re-treatment (Table 1); (7) a corneal cap with a 7.78-mm diameter has a greater risk of suction loss than a cap with a 7.60-mm diameter; (8) when lenticular scanning exceeds $10 \%$, SMILE surgery can be continued by changing the thickness of the corneal cap; (9) preventive SMILE Xtra caps are 90-120 $\mu \mathrm{m}$ thick and 7-7.8 $\mathrm{mm}$ in diameter. For patients with high myopic correction and a thin cornea, it is a favorable choice to design the stromal pocket according to the shape (thickness and diameter) of the corneal cap for SMILE Xtra; and (10) by properly treating cap-related complications, such as cap perforation, cap lenticular adhesion, and cap striae, the majority of patients shall obtain better postoperative results.

In the future, the long-term biomechanical changes due to different cap thicknesses, the smoothness of lenses, and the significance represented by Bowman's membrane microfold should be further studied. In addition, further research on the optical density of the corneal cap [8] and the application of LE for presbyopia [87] is need- ed. As ophthalmologists gain a deeper understanding of corneal caps, the depth and diameter of the caps may be personalized according to the patient's condition, which would benefit more patients with thin corneas and high myopia and may reduce the incidence of complications.

\section{Conflict of Interest Statement}

The authors have no conflicts of interest to declare.

\section{Funding Sources}

Yan Zhang was supported by an unrestricted grant from the Jilin Provincial Science and Technology Department InternationalScience and Technology Cooperation Project (20200801016GH), Natural Science Foundation of Science and Technology Department of Jilin Province (20180101146JC), Youth Talent Training Project of Jilin Provincial Department of Finance (3D5197389429), Jilin Province traditional Chinese Medicine Science and Technology Support Project (2019134), Mechanism of BMP4 Inhibiting Corneal Neovascularization (3R2196623429), and Course Cases Base of Professional Degree Graduate (419100200379); Yuxi He was supported by an unrestricted grant from the Jilin Medical and Health Talents Special Project (2019SCZT052 and 2019SCZT057) and Outstanding Young Teacher Training Program of Jilin University (419080500586 and 419080520252); Shurong Wang was supported by an unrestricted grant from the Jilin Provincial Science and Technology Department International Science and Technology Cooperation Project (20180414063GH), Science and Technology Research Project of Jilin Provincial Education Department (JJKH20201103KJ), and Fundamental Scientific Research Business Expenses Project of Jilin University (45119031C004).

\section{Author Contributions}

Chen Liang and Yan Zhang share the first authorship and contributed to the conception and design, data collection, analysis and interpretation of data, and writing the manuscript. Yuxi He contributed to critical revision of the manuscript. Shurong Wang is the corresponding author.

\section{References}

1 Moshirfar M, McCaughey MV, Reinstein DZ, Shah R, Santiago-Caban L, Fenzl CR. Smallincision lenticule extraction. J Cataract Refract Surg. 2015;41(3):652-65.

2 Luft N, Schumann RG, Dirisamer M, Kook D, Siedlecki J, Wertheimer C, et al. Wound healing, inflammation, and corneal ultrastructure after SMILE and femtosecond laser-assisted LASIK: a human ex vivo study. J Refract Surg. 2018;34(6):393-9.
3 Reinstein DZ, Archer TJ, Randleman JB. Mathematical model to compare the relative tensile strength of the cornea after PRK, LASIK, and small incision lenticule extraction. J Refract Surg. 2013;29(7):454-60.

4 Li H, Wang Y, Dou R, Wei P, Zhang J, Zhao $\mathrm{W}$, et al. Intraocular pressure changes and relationship with corneal biomechanics after SMILE and FS-LASIK. Invest Ophthalmol Vis Sci. 2016;57(10):4180-6.
5 Ishii R, Shimizu K, Igarashi A, Kobashi H, Kamiya K. Influence of femtosecond lenticule extraction and small incision lenticule extraction on corneal nerve density and ocular surface: a 1-year prospective, confocal, microscopic study. J Refract Surg. 2015; 31(1):10-5 
6 Zhao J, Yao P, Li M, Chen Z, Shen Y, Zhao Z, et al. The morphology of corneal cap and its relation to refractive outcomes in femtosecond laser small incision lenticule extraction (SMILE) with anterior segment optical coherence tomography observation. PLoS One. 2013;8(8):e70208.

7 Fu D, Wang L, Zhou XT, Yu ZQ. Cap morphology after small-incision lenticule extraction and its effects on intraocular scattering. Int J Ophthalmol. 2018;11(3):456-61.

8 Alio Del Barrio JL, Parafita-Fernandez A, Canto-Cerdan M, Alio JL, Teus M. Evolution of corneal thickness and optical density after laser in situ keratomileusis versus small incision lenticule extraction for myopia correction. Br J Ophthalmol. 2020. Epub ahead of print.

9 Olsen MV, Lyngstadaas AV, Zhou W, Stojanovic A, Utheim TP, Wang X, et al. Temporal redistribution of cap and residual stromal thickness after SMILE. J Cataract Refract Surg. 2020;46(10):1331-8.

10 Reinstein DZ, Archer TJ, Gobbe M. Accuracy and reproducibility of cap thickness in small incision lenticule extraction. J Refract Surg. 2013;29(12):810-5.

11 Thomas J, Wang J, Rollins AM, Sturm J. Comparison of corneal thickness measured with optical coherence tomography, ultrasonic pachymetry, and a scanning slit method. J Refract Surg. 2006;22(7):671-8.

12 Mohamed-Noriega K, Riau AK, Lwin NC, Chaurasia SS, Tan DT, Mehta JS. Early corneal nerve damage and recovery following small incision lenticule extraction (SMILE) and laser in situ keratomileusis (LASIK). Invest Ophthalmol Vis Sci. 2014;55(3):1823-34.

13 Shah R, Shah S. Effect of scanning patterns on the results of femtosecond laser lenticule extraction refractive surgery. J Cataract Refract Surg. 2011;37(9):1636-47.

14 Heichel J, Blum M, Duncker GI, Sietmann R, Kunert KS. Surface quality of porcine corneal lenticules after femtosecond lenticule extraction. Ophthalmic Res. 2011;46(2):107-12.

15 Qazi MA, Roberts CJ, Mahmoud AM, Pepose JS. Topographic and biomechanical differences between hyperopic and myopic laser in situ keratomileusis. J Cataract Refract Surg. 2005;31(1):48-60.

16 Holzer MP, Rabsilber TM, Auffarth GU. Femtosecond laser-assisted corneal flap cuts: morphology, accuracy, and histopathology. Invest Ophthalmol Vis Sci. 2006;47(7):282831.

17 Binder PS. Flap dimensions created with the IntraLase FS laser. J Cataract Refract Surg. 2004;30(1):26-32.

18 Gyldenkerne A, Ivarsen A, Hjortdal JØ. Comparison of corneal shape changes and aberrations induced By FS-LASIK and SMILE for myopia. J Refract Surg. 2015;31(4):223-9.

19 Qin B, Li M, Chen X, Sekundo W, Zhou X. Early visual outcomes and optical quality after femtosecond laser small-incision lenticule extraction for myopia and myopic astigmatism correction of over - 10 dioptres. Acta Ophthalmol. 2018;96(3):e341-6.

20 Xia F, Shen Y, Han T, Zhao J, Xu H, Zhou X. Small Incision Lenticule Extraction (SMILE) for moderate and high myopia: seven-year outcomes of refraction, corneal tomography, and wavefront aberrations. J Ophthalmol. 2020;2020:3825864.

21 Yang X, Liu F, Liu M, Liu Q, Weng S, Lin H. 15 -month visual outcomes and corneal power changes of SMILE in treating high myopia with maximum myopic meridian exceeding 10.00 D. J Refract Surg. 2019;35(1):31-9.

22 Damgaard IB, Ivarsen A, Hjortdal J. Refractive correction and biomechanical strength following SMILE with a 110 - or $160-\mu \mathrm{m}$ cap thickness, evaluated ex vivo by inflation test. Invest Ophthalmol Vis Sci. 2018;59(5):183643.

23 Wu D, Liu C, Li B, Wang D, Fang X. Influence of cap thickness on corneal curvature and corneal biomechanics after SMILE: a Prospective, Contralateral Eye Study. J Refract Surg. $2020 ; 36(2): 82-8$.

24 Guell JL, Verdaguer P, Mateu-Figueras G, Elies D, Gris O, El Husseiny MA, et al. SMILE procedures with four different cap thicknesses for the correction of myopia and myopic astigmatism. J Refract Surg. 2015;31(9):5805.

25 Weng S, Liu M, Yang X, Liu F, Zhou Y, Lin H, et al. Evaluation of human corneal lenticule quality after SMILE with different cap thicknesses using scanning electron microscopy. Cornea. 2018;37(1):59-65.

26 Ma J, Wang Y, Wei P, Jhanji V. Biomechanics and structure of the cornea: implications and association with corneal disorders. Surv Ophthalmol. 2018;63(6):851-61.

27 Holladay JT, Janes JA. Topographic changes in corneal asphericity and effective optical zone after laser in situ keratomileusis. J Cataract Refract Surg. 2002;28(6):942-7.

28 Winkler M, Chai D, Kriling S, Nien CJ, Brown DJ, Jester B, et al. Nonlinear optical macroscopic assessment of 3-D corneal collagen organization and axial biomechanics. Invest Ophthalmol Vis Sci. 2011;52(12):8818-27.

29 Morishige N, Shin-Gyou-Uchi R, Azumi H, Ohta H, Morita Y, Yamada N, et al. Quantitative analysis of collagen lamellae in the normal and keratoconic human cornea by second harmonic generation imaging microscopy. Invest Ophthalmol Vis Sci. 2014;55(12): 8377-85.

$30 \mathrm{Wu}$ F, Yin H, Yang Y. Contralateral eye comparison between 2 cap thicknesses in small incision lenticule extraction: 110 versus $130 \mu \mathrm{m}$. Cornea. 2019;38(5):617-23.

31 Liu M, Zhou Y, Wu X, Ye T, Liu Q. Comparison of 120- and 140- $\mu \mathrm{m}$ SMILE cap thickness results in eyes with thick corneas. Cornea. 2016;35(10):1308-14.

32 He M, Wang W, Ding H, Zhong X. Comparison of two cap thickness in small incision lenticule extraction: $100 \mu \mathrm{m}$ versus $160 \mu \mathrm{m}$. PLoS One. 2016;11(9):e0163259.
33 Liu T, Yu T, Liu L, Chen K, Bai J. Corneal cap thickness and its effect on visual acuity and corneal biomechanics in eyes undergoing small incision lenticule extraction. J Ophthalmol. 2018;2018:6040873.

34 El-Massry AA, Goweida MB, Shama A-S, Elkhawaga MH, Abdalla MF. Contralateral eye comparison between femtosecond small incision intrastromal lenticule extraction at depths of 100 and $160 \mu \mathrm{m}$. Cornea. 2015; 34(10):1272-5.

35 Luz A, Faria-Correia F, Salomão MQ, Lopes BT, Ambrósio R Jr. Corneal biomechanics: Where are we? J Curr Ophthalmol. 2016; 28(3):97-8.

36 Zhao Y, Li M, Zhao J, Knorz MC, Sun L, Tian $\mathrm{M}$, et al. Posterior corneal elevation after small incision lenticule extraction for moderate and high myopia. PLoS One. 2016;11(2): e0148370.

37 Wu D, Li B, Huang M, Fang X. Influence of cap thickness on opaque bubble layer formation in SMILE: 110 versus $140 \mu \mathrm{m}$. J Refract Surg. 2020;36(9):592-6.

38 Yang W, Li M, Fu D, Wei R, Cui C, Zhou X. A comparison of the effects of different cap thicknesses on corneal nerve destruction after small incision lenticule extraction. Int Ophthalmol. 2020;40(8):1905-11.

39 Torun Acar B, Acar S. Effect of cap-lenticule diameter difference on the visual outcome and higher-order aberrations in SMILE: 0.4 $\mathrm{mm}$ versus $1.0 \mathrm{~mm}$. J Ophthalmol. 2017;2017: 8259546.

40 Siedlecki J, Luft N, Kook D, Wertheimer C, Mayer WJ, Bechmann M, et al. Enhancement after myopic Small Incision Lenticule Extraction (SMILE) using surface ablation. J Refract Surg. 2017;33(8):513-8.

41 Reinstein DZ, Carp GI, Archer TJ, Vida RS. Outcomes of re-treatment by LASIK after SMILE. J Refract Surg. 2018;34(9):578-88.

42 Liu YC, Rosman M, Mehta JS. Enhancement after small-incision lenticule extraction: incidence, risk factors, and outcomes. Ophthalmology. 2017;124(6):813-21.

43 Siedlecki J, Luft N, Mayer WJ, Siedlecki M, Kook D, Meyer B, et al. CIRCLE enhancement after myopic SMILE. J Refract Surg. 2018;34(5):304-9.

44 Siedlecki J, Siedlecki M, Luft N, Kook D, Meyer B, Bechmann M, et al. Surface ablation versus CIRCLE for myopic enhancement after SMILE: a Matched Comparative Study. J Refract Surg. 2019;35(5):294-300.

45 Reinstein DZ, Carp GI, Archer TJ, Vida RS. Outcomes of re-treatment by LASIK after SMILE. J Refract Surg. 2018;34(9):578-88.

46 Ganesh S, Brar S, Relekar KJ. Epithelial thickness profile changes following Small Incision Refractive Lenticule Extraction (SMILE) for myopia and myopic astigmatism. J Refract Surg. 2016;32(7):473-82.

47 Siedlecki J, Luft N, Priglinger SG, Dirisamer M. Enhancement options after myopic Small-Incision Lenticule Extraction (SMILE): a review. Asia Pac J Ophthalmol. 2019;8(5):406-11. 
48 Riau AK, Liu YC, Lim CHL, Lwin NC, Teo EP, Yam GH, et al. Retreatment strategies following Small Incision Lenticule Extraction (SMILE): in vivo tissue responses. PLoS One. 2017;12(7):e0180941.

49 Moshirfar M, Shah TJ, Masud M, Linn SH, Ronquillo Y, Hoopes PC, et al. Surgical options for retreatment after small-incision lenticule extraction: advantages and disadvantages. J Cataract Refract Surg. 2018;44(11): 1384-9.

50 Donate $\mathrm{D}$, Thaëron R. Preliminary evidence of successful enhancement after a primary SMILE procedure with the sub-cap-lenticuleextraction technique. J Refract Surg. 2015; 31(10):708-10.

51 Mattila JS, Holopainen JM. Bilateral ectasia after femtosecond laser-assisted Small Incision Lenticule Extraction (SMILE). J Refract Surg. 2016;32(7):497-500.

52 Sinha Roy A, Shetty R. Ectasia after SMILE: correct interpretation of biomechanical hypothesis. J Refract Surg. 2017;33(1):66.

53 Voulgari N, Mikropoulos D, Kontadakis GA, Safi A, Tabibian D, Kymionis GD. Corneal scarring and hyperopic shift after corneal cross-linking for corneal ectasia after SMILE. J Refract Surg. 2018;34(11):779-82.

54 Gaster RN, Caiado Canedo AL, Rabinowitz YS. Corneal collagen cross-linking for keratoconus and post-LASIK ectasia. Int Ophthalmol Clin. 2013;53(1):79-90.

55 Kim TI, Alió Del Barrio JL, Wilkins M, Cochener B, Ang M. Refractive surgery. Lancet. 2019;393(10185):2085-98.

$56 \mathrm{Ng}$ AL, Chan TC, Cheng GP, Jhanji V, Ye C, Woo VC, et al. Comparison of the early clinical outcomes between combined small-incision lenticule extraction and collagen crosslinking versus SMILE for myopia. J Ophthalmol. 2016;2016:2672980.

57 Liu C, Wang Z, Wu, Luo T, Su Y, Mo J, et al. Comparison of 1 -year outcomes between small incision lenticule extraction with prophylactic cross-linking and femtosecond laser-assisted in situ keratomileusis with prophylactic cross-linking. Cornea. 2021;40(1): 12-8.

58 Ganesh S, Brar S. Clinical outcomes of small incision lenticule extraction with accelerated cross-linking (ReLEx SMILE Xtra) in patients with thin corneas and borderline topography. J Ophthalmol. 2015;2015:263412.

59 Konstantopoulos A, Liu YC, Teo EP, Nyein CL, Yam GH, Mehta JS. Corneal stability of LASIK and SMILE when combined with collagen cross-linking. Transl Vis Sci Technol. 2019;8(3):21

60 Osman IM, Helaly HA, Abou Shousha M, AbouSamra A, Ahmed I. Corneal safety and stability in cases of small incision lenticule extraction with collagen cross-linking (SMILE Xtra). J Ophthalmol. 2019;2019:6808062.
61 Zhou Y, Liu M, Zhang T, Zheng H, Sun Y, Yang $\mathrm{X}$, et al. In vivo confocal laser microscopy of morphologic changes after small incision lenticule extraction with accelerated cross-linking (SMILE Xtra) in patients with thin corneas and high myopia. Graefes Arch Clin Exp Ophthalmol. 2018;256(1):199-207.

62 Lombardo M, Lombardo G, Carbone G, De Santo MP, Barberi R, Serrao S. Biomechanics of the anterior human corneal tissue investigated with atomic force microscopy. Invest Ophthalmol Vis Sci. 2012;53(2):1050-7.

63 Muller LJ, Pels E, Vrensen GF. The specific architecture of the anterior stroma accounts for maintenance of corneal curvature. $\mathrm{Br} \mathrm{J}$ Ophthalmol. 2001;85(4):437-43

64 Wollensak G, Aurich H, Pham DT, Wirbelauer C. Hydration behavior of porcine cornea crosslinked with riboflavin and ultraviolet A. J Cataract Refract Surg. 2007;33(3):51621.

65 Park JH, Koo HJ. Comparison of immediate small-incision lenticule extraction after suction loss with uneventful small-incision lenticule extraction. J Cataract Refract Surg. 2017; 43(4):466-72.

66 Liu M, Wang J, Zhong W, Wang D, Zhou Y, Liu Q. Impact of suction loss during Small Incision Lenticule Extraction (SMILE). J Refract Surg. 2016;32(10):686-92.

67 Osman IM, Awad R, Shi W, Abou Shousha M. Suction loss during femtosecond laser-assisted small-incision lenticule extraction: Incidence and analysis of risk factors. J Cataract Refract Surg. 2016;42(2):246-50.

68 Wang Y, Ma J, Zhang J, Dou R, Zhang H, Li $\mathrm{L}$, et al. Incidence and management of intraoperative complications during small-incision lenticule extraction in 3004 cases. J Cataract Refract Surg. 2017;43(6):796-802.

69 Reinstein DZ, Archer TJ, Vida RS, Carp GI Suction stability management in small incision lenticule extraction: incidence and outcomes of suction loss in 4000 consecutive procedures. Acta Ophthalmol. 2020;98(1):e72-80.

70 Qin B, Li M, Shen Y, Zeng L, Wang X, Sekundo W, et al. Management of suction loss during SMILE in 12,057 eyes: incidence, outcomes, risk factors, and a novel method of same-day recutting of refractive lenticules. J Refract Surg. 2020;36(5):308-16.

71 Ivarsen A, Asp S, Hjortdal J. Safety and complications of more than 1500 small-incision lenticule extraction procedures. Ophthalmology. 2014;121(4):822-8.

72 Ma JN, Wang Y, Zhang L, Zhang JM. [Clinical study of suction loss in small incision lenticule extraction]. Zhonghua Yan Ke Za Zhi. 2018;54(12):890-6. 30526787.

73 Asif MI, Bafna RK, Mehta JS, Reddy J, Titiyal JS, Maharana PK, et al. Complications of small incision lenticule extraction. Indian J Ophthalmol. 2020;68(12):2711-22.
74 Reinstein DZ, Archer TJ, Vida RS, Carp GI. Suction stability management in SMILE: development of a decision tree for managing eye movements and suction loss. J Refract Surg. 2018;34(12):809-16.

75 Ramirez-Miranda A, Ramirez-Luquin T, Navas A, Graue-Hernandez EO. Refractive lenticule extraction complications. Cornea. 2015;34(Suppl 10):S65-7.

76 Titiyal JS, Kaur M, Rathi A, Falera R, Chaniyara M, Sharma N. Learning curve of small incision lenticule extraction: challenges and complications. Cornea. 2017;36(11):1377-82.

77 Jacob S, Nariani A, Figus M, Agarwal A, Agarwal A. White ring sign for uneventful lenticule separation in small-incision lenticule extraction. J Cataract Refract Surg. 2016;42(9): 1251-4.

78 Shetty R, Negalur N, Shroff R, Deshpande K, Jayadev C. Cap lenticular adhesion during small incision lenticular extraction surgery: causative factors and outcomes. Asia Pac J Ophthalmol. 2017;6(3):233-7.

79 Titiyal JS, Kaur M, Brar AS, Falera R. "Meniscus sign" to identify the lenticule edge in small-incision lenticule extraction. Cornea. 2018;37(6):799-801.

80 Sachdev GS, Ramamurthy S, Dandapani R. Stop sign for correct tissue plane identification in small incision lenticule extraction. Indian J Ophthalmol. 2020;68(5):895-6.

81 Kim BK, Mun SJ, Lee DG, Choi HT, Chung YT. Chung's swing technique: a new technique for small-incision lenticule extraction. BMC Ophthalmol. 2016;16(1):154.

82 Titiyal JS, Kaur M, Shaikh F, Sahay P. Double crescentic edge separation for the management of cap-lenticular adhesion in small incision lenticule extraction. Indian J Ophthalmol. 2020;68(5):897-9.

83 Ng ALK, Cheng GPM, Woo VCP, Jhanji V, Chan TCY. Comparing a new hydroexpression technique with conventional forceps method for SMILE lenticule removal. $\mathrm{Br} J$ Ophthalmol. 2018;102(8):1122-6.

84 Titiyal JS, Rathi A, Kaur M, Falera R. AS-OCT as a rescue tool during difficult lenticule extraction in SMILE. J Refract Surg. 2017;33(5): $352-4$.

85 Ganesh S, Brar S, Lazaridis A. Management and outcomes of retained lenticules and lenticule fragments removal after failed primary SMILE: a case series. J Refract Surg. 2017; 33(12):848-53.

86 Ganesh S, Ganesh SS, Gaster R, Brar S. Management of cap striae following challenging small incision lenticule extraction surgery: a case report. Indian J Ophthalmol. 2020; 68(12):3060-1.

87 Jacob S, Kumar DA, Agarwal A, Agarwal A, Aravind R, Saijimol AI. Preliminary evidence of successful near vision enhancement with a new technique: PrEsbyopic Allogenic Refractive Lenticule (PEARL) corneal inlay using a SMILE lenticule. J Refract Surg. 2017;33(4): 224-9. 